\title{
LEADERSHIP SKILLS: A STUDY IN HOCHIMINH CITY, VIETNAM
}

\author{
Tran Thi Bich Nhung ${ }^{1}$ \\ ${ }^{1}$ Foreign Trade University Hochiminh city branch, 15 D5 Street 25 Ward Binh Thanh District, \\ HochiminhCity, 084, Vietnam, tranthibichnhung.cs2@ftu.edu.vn, (0938028655)
}

\begin{abstract}
Leadership skills have long been a topic of interest in the leadership literature (Mumford et al., 2007), leadership skills are essential for the survival and development of businesses, impact leaders' behaviors, effectiveness and performance (Connelly et al. 2000; Marcy and Mumford 2010). This article focuses on (1) assessing leadership skills at Vietnam enterprises and (2) studying the differences in genders, position, and experience about leadership skills of companies in Vietnam. In order to clarify the above research issues, this paper uses analysis, synthesis, critical thinking methods combined with Cronbach's Alpha, EFA, CFA, MANCOVA analysis through SPSS and AMOS statistics. The results show that leadership skills at enterprises in Vietnam can be measured through cognitive skills, interpersonal skills, business skills and strategic skills. In general, leadership skills are above average, and Cognitive skills are assessed best, followed by strategic skills and business skills, and the worst assessed skill is human skill. In terms of gender, male leaders have higher cognitive skills than female leaders, but female leaders, on the other hand, outperform male leaders in human skills. About position, the higher the leadership levels are, the higher leadership skills are, there is no significant difference in human skills at level. In experience, leaders who have more experience get higher leadership skills, especially strategic skills and business skills.
\end{abstract}

\section{Keywords}

Leadership skills; Skills of leaders; Leadership skills measurement; Leadership skills: differences in gender, position and experience; Leadership skills in Vietnam

\section{JEL Classification}

C52

DOI: https://doi.org/10.14311/bit.2019.02.03

Editorial information: journal Business \& IT, ISSN 2570-7434, CreativeCommons license (c) (i) published by CTU in Prague, 2019, http://bit.fsv.cvut.cz/ 


\section{Introduction}

Leaders are indispensable people in any business. They perform leadership function in the business, run the company, determine goals, orient operation and plan the vision of the company. At the same time, leaders can affect, inspire employees, colleagues and business leaders to dedicate themselves to the company. In addition, leaders are those who have great influence on individuals and organizations outside the company to ensure that the set goals of the business can be achieved. Among leadership factors, leadership skill is considered the most important, because they can make leaders become better (Mumford et al., 2007), leadership skills impact leaders' behaviors, effectiveness and performance (Connelly et al. 2000; Marcy and Mumford 2010), leadership skills also contribute greatly to creativity and innovation in organizational settings, and finally, these skills help leaders who are coping with complex environments and contribute to team performance.

Because of its great importance, issues of leadership skill have long received a lot of attention from scholars. In terms of research content, leadership researches can be divided into two groups. The first is exploratory researches to identify important skills that a person will pursue as a leader or an informal leader in one group (Katz 1955; Lord, De Vader and Alliger 1986; Stogdill 1974; Mumford et al 2000; Moore, LL, and Rudd, R. D 2004; Mumford, Campion and Morgeson 2007; Hung, NM, Tesaputa, K., \& Sri-ampai 2014; Da'as, R.A 2017). And the second is researches on the relationship between leadership skills and leadership effectiveness in the current management position of leaders (Cheng, HC 2011; Kehinde, J. S Jegede, CA and Akinladi, HB 2012; Connelly et al. 2000). In terms of fields, leadership skill studies are conducted in a variety of areas, such as the military (Zaccaro et al. 2000); education (Kalargyrou et al., 2012; Da'as, R. A. 2016; Hung, N. M., Tesaputa, K., \& Sri-ampai 2014); (Zilz et al. 2004; Robbins et al. 2001); (Kehinde, J.S. et al., 2012), public services (Haq, S. 2011). Studies have shown that factors such as gender, management level and experience affect leadership (Eagly, Karau, and Makhijani 1995; Katz 1955; Mumford, TV, Campion, MA, \& Morgeson, FP 2007; Mumford et al. 2000).

In Vietnam, the majority of studies on leadership focused on leadership competences and leadership styles. A few authors study the personal traits of the leader, the role of corporate directors in Vietnamese economy and other issues such as research on the relationship between threedimensional leadership and business performance in Vietnam. Direct research on leadership skills includes PhD thesis on leadership development in non-state enterprises of Vietnam by Nguyen Thi Thu Trang (2016) and the article on leadership skills of the deans at a regional university in Vietnam posted at the 7th International Education Reform Conference (ICER 2014) of Hung, NM, et al. (2014).

This article focuses on two purposes, includes assessing leadership skills at Vietnam enterprises and studying the differences in genders, position, and experience about leadership skills of companies in Vietnam.

\section{Theoretical framework}

Researchers usually define leadership according to their individual perspective and the aspect of the phenomenon of most interest to them, so there are many different definitions of leadership (Yukl, 2013). Leadership is the influential increment over and above mechanical compliance with the routine directives of the organization, Leadership is the relationship of influence between leaders and leaders to implement current change, which is a reflection of their goals (Rost 1993), leadership is the ability of an individual to influence, motivate, and enable others to contribute toward the effectiveness and success of the organization (House et al. 1999), Leadership is the process of influencing others to 
understand and agree about what needs to be done and how to do it, and the process of facilitating individual and collective efforts to accomplish shared objectives (Yukl, 2013). Most definitions of leadership involve an influence process, but the numerous definitions of leadership that have been proposed appear to have little else in common. In research, the operational definition of leadership depends on a great extent on the purpose of the researcher (Campell, 1977), and it is very difficult to settle on a single definition of leadership that is general enough to accommodate these many meanings and specific enough to serve as an operationalization of the variable (Karmel 1978). This article uses the leadership definition of Yukl to study. And the terms leader, manager are used interchangeably to indicate people who occupy positions in which they are expected to perform the leadership role.

Skill is an ambiguous and complex concept. Skills encompass mental and physical proficiency, as well as physical dexterity. Skill is not only the ability to do something but the word implies a dimension of increasing ability (Attewell 1990). According to the Society for Human Resource Management (2008), skills are the ability to perform a mental or motor activity that contributes to the effective performance of a job task. Besides, skill implies an ability which can be learned and developed, not necessarily inborn, and which is manifested in performance, not merely in potential (Katz 1955; Northouse 2007). The term skill refers to the ability to do something in an effective manner, and may be defined at different levels of abstraction, ranging from general, broadly - defined abilities to narrower, more specific abilities (Yulk, 2013). Leadership skills in this paper mean skills of leaders, are the abilities of leader to do something in an effective manner to perform the leadership role.

Based on observations of executives at work and field research in administration, Katz (1955) identified three categories of skills needed by leaders, including technical skills, human skills, and conceptual skills. Technical skills include knowledge about methods, processes, procedures, and techniques for conducting a specialized activity, and the ability to use tools and equipment relevant to that activity. Technical skills also include factual knowledge about the organization and knowledge about the products and services of the organization. This type of knowledge is acquired by a combination of formal education, training, and job experience. Human skills include knowledge about human behavior and interpersonal processes, ability to understand the feeling, attitudes, and motives of others from what they say and do (empathy, social sensitivity), ability to communicate clearly and effectively (speech fluency, persuasiveness), and ability to establish effective and cooperative relationships (tact, diplomacy, listening skill, knowledge about acceptable social behavior). Conceptual skills involve general analytical abilities, logical thinking, proficiency in concept formation and conceptualization of complex and ambiguous relationships, creativity in idea generation and problem solving, ability to analyze events and perceive trends, anticipate changes and recognize opportunities and potential problems. Technical skills are more important at the lower levels of administration, conceptual skills are more important at the higher levels and human skills are needed for all levels of leadership.

Mumford et al., (2000) suggested that leaders need problem solving skills and social judgment skills, but to effectively apply these skills leaders need to have knowledge about works, organization, business and human knowledge. In addition, Mumford et al., (2000) also found that individual characteristics of leadership such as integrated thinking ability, cognitive thinking ability, motivation and personality of the leader influence the leadership skills and knowledge. In addition, the authors emphasize that the skills, knowledge, and personal characteristics of the leader will be governed by the professional experience of the leader, and environmental factors.

The strataplex model of Mumford, Campion và Morgeson (2007), based on previous conceptualizations of leadership skill requirements, suggested leadership in terms of four general skills: 
(1) Cognitive skills, (2) Interpersonal skills, (3) Business skills, and (4) Strategic skills. Cognitive skills are the foundation of the leadership skill requirements. They are comprised of those skills related to basic cognitive capacities, such as collecting, processing, disseminating information, learning, and are the fundamental skills required for a large portion of the activities in which leaders are engaged. Interpersonal skills involve social perceptiveness to allow for an awareness of other's reactions and understanding of why they react the way they do, also includes the skills required for coordination of actions of oneself and other, and negotiation skills to reconcile differences among employee perspectives and establish mutually satisfying relationships, and persuasion skills to influence other to more effectively accomplish organizational objectives. Business skills involve the management of material resources, operations analysis, personnel resources and financial resources. Strategic skills are high conceptual skills needed to take a systems perspective to understand complexity, deal with ambiguity, and to effect influence in the organization. These include the skills of visioning, systems perception, identification of downstream consequences and identification of key causes, problem identification, solution appraisal and objective evaluation.

\section{Methodology}

This paper uses the Mumford et al, (2007) measurement which is based on the Occupational Information Network (O*NET) scales developed by the US department of Labor to assess leadership skills in Vietnam. After discussions with some leaders in pilot study, measurements are adjusted according to Vietnamese leaders.

Cognitive skills were assessed using seven items including: speaking (talking to others to convey information effectively), listening (listening to what other people are saying), asking questions(asking appropriate questions after listening to what other people said), writing (communicating effectively in writing as appropriate for the needs of audience), reading comprehension (understanding written sentences and paragraphs in work related documents), active learning (working with new information to grasp its implications) and critical thinking (using logic and analysis to identify the strengths and weaknesses of different approaches).

Interpersonal skills were assessed using four following items: social perceptiveness (being aware of other's reactions and understanding why they react as they do), coordination (adjusting actions in relation to other's actions), negotiation (bringing others together to reconcile differences), and persuasion (persuading others to change their minds or behavior)

Business skills were measured using four items including: operations analysis (analyzing needs and product requirements to create a design), management of personnel resources (motivating, developing, and directing people as they work), financial resources management (determining how money will be spent to get the work done), and material resources management (obtaining and seeing to the appropriate use of equipment, facilities, and materials needed to do certain work).

Strategic skills were measured using seven following items: Visioning (developing an image of how a system should work under ideal conditions), systems perception (determining when important changes have occurred in a system or are likely to occur), system evaluation (looking at many indicators of system performance, taking into account their accuracy), identification of downstream consequences (determining the long - term outcomes of a change in operations), key causes identification (identifying the things that must be changed to achieve a goal), problem identification (identifying the nature of problems), and solution appraisal (observing and evaluating the outcomes of problem solution to identify lessons learned or redirect efforts) 
The sample consisted of 314 leaders working at companies in Ho Chi Minh City - Vietnam, and these leaders have differences in fields, in gender (178 male and 136 female leaders), position (101senior, $154 \mathrm{mid}$, and 59 junior level leaders), and experience years as leader job (61 leaders under 5 experience years, 141 leaders from 5 to under 10 experience years, and 112 leaders from 10 experience years).

To ensure objectivity in research, all items were coded as follows: Cognitive skills (Cog), speaking $(\operatorname{cog} 1)$, listen $(\operatorname{cog} 2)$, ask questions $(\operatorname{cog} 3)$, writing $(\operatorname{cog} 4)$, reading comprehension $(\operatorname{cog} 5)$, active learning ( $\operatorname{Cog} 6)$, critical thinking ( $\operatorname{cog} 7)$. Interpersonal skills (per), social perceptiveness (per1), coordination (per2), negotiation (per3), and persuasion (per4). Business skills (bus), operations analysis (bus1), management of personnel resources (bus2), financial resources management (bus3), and material resources management (bus4). Strategic Skills (Str), visioning (str1), systems perception (str2), system evaluation (str3), identification of downstream consequences (str4), key causes identification (str5), problem identification (str6), and solution appraisal (str7).

The items were ranked on a 5 - degree Likert scale describing the self - assessment of leaders of the abilities to do the tasks, ranking from 1 (very bad) to 5 (very good). The article used Cronbach's Alpha, Exploratory Factor Analysis (EFA) and Confirmatory Factor Analysis (CFA) to evaluate the leadership skills model, and used MANCOVA to test differences in gender, position and experience years.

The reliability of the scale is accepted when Cronbach Alpha $\geq 0.60$ and the total correlation coefficient $\geq 0.30$ (Nunnally \& Bernstein 1994). For the reliability of the scale, the article uses the Principal axis factoring method with promax rotation, with stops when extracting elements with eigenvalue $\geq 1$. The $K M O$ is in the range of $0.5 \leq K M O \leq 1$, it is possible to see the factor analysis as appropriate. Bartlett's test with a significance level $\leq 0.05$, it is possible to see correlated variables in the overall (Anderson and Gerbing 1988). The scale is acceptable when the total variance is $\geq 50 \%$, load factor $\geq 0.4$. For CFA tests, the article accepts the chi-square test with P-value $<0.05 ; \mathrm{TLI}, \mathrm{CFI}, \mathrm{GFI} \geq 0.9$ values (Bentler and Bonett 1980); CMIN / df <2 or possibly <3 (Mclver and Carmines 1981); and RMSEA $<0.08$ (Steiger 1990). Scales in CFA were accepted when composite reliability >0.6, AVE deviation >0.5, convergence validity and discriminant validity are available.

\section{Results}

The first Cronbach's Alpha test shows four items, including written, active learning, coordinate, systems perception skills are not valid. The Cronbach's Alpha of the second test after removing above un-valid items were 0.806 for cognitive skills, 0.846 for interpersonal skills, 0.824 business skills, and 0.864 for strategic skills. Item - total correlation of items were speaking $(0.681)$, listening $(0.583)$, ask questions (0.430), reading comprehension (0.655), critical thinking (0.608), social perceptiveness (0.724), negotiation (0.703), and persuasion (0.720), operations analysis (0.571), management of personnel resources (0.736), financial resources management $(0.626)$, and material resources management (0.666), Visioning (0.599), system evaluation (0.717), identification of downstream consequences (0.617), key causes identification (0.610), problem identification (0.715), and solution appraisal (0.702)

EFA analysis shows that Kaiser-Meyer-Olkin Measure of Sampling Adequacy $=0.834$;Bartlett's Test of Sphericity with Sig $=0.000$, Eigenvalues $=63.770 \%$ and pattern matrix is showed detail in Table 1.

The first CFA analysis shows that $p-$ value of the chi - square test $=0.000, C M I N / D F=2.351, T L I$ $=0.912, \mathrm{CFI}=0.926, \mathrm{GFI}=0.903, \mathrm{AGFI}=0.871, \mathrm{RMSEA}=0.066, \mathrm{PCLOSE}=0.004$. Standardized Regression 
Weights of $\operatorname{Cog} 3$ item $=0.467$, so item Cog3 was removed. The result of the second CFA analysis showed that $p$ - value of the chi - square test $=0.000, \mathrm{CMIN} / \mathrm{DF}=1.850 ; \mathrm{TLI}=0.948, \mathrm{CFI}=0.957, \mathrm{GFI}=0.926$, AGFI $=0.900$, RMSEA $=0.052, \mathrm{PCLOSE}=0.364 . \mathrm{P}-$ Value of convergent Validity (details are showed in table 2)< 0.01; P-value of discriminant validity(details are indicated in table 3 ) $<0.01$, composite reliability $>0.8$ and average variance extracted $>0.5$ (details are showed in table 4 ). The details result of CFA test is shown in Fig 1.

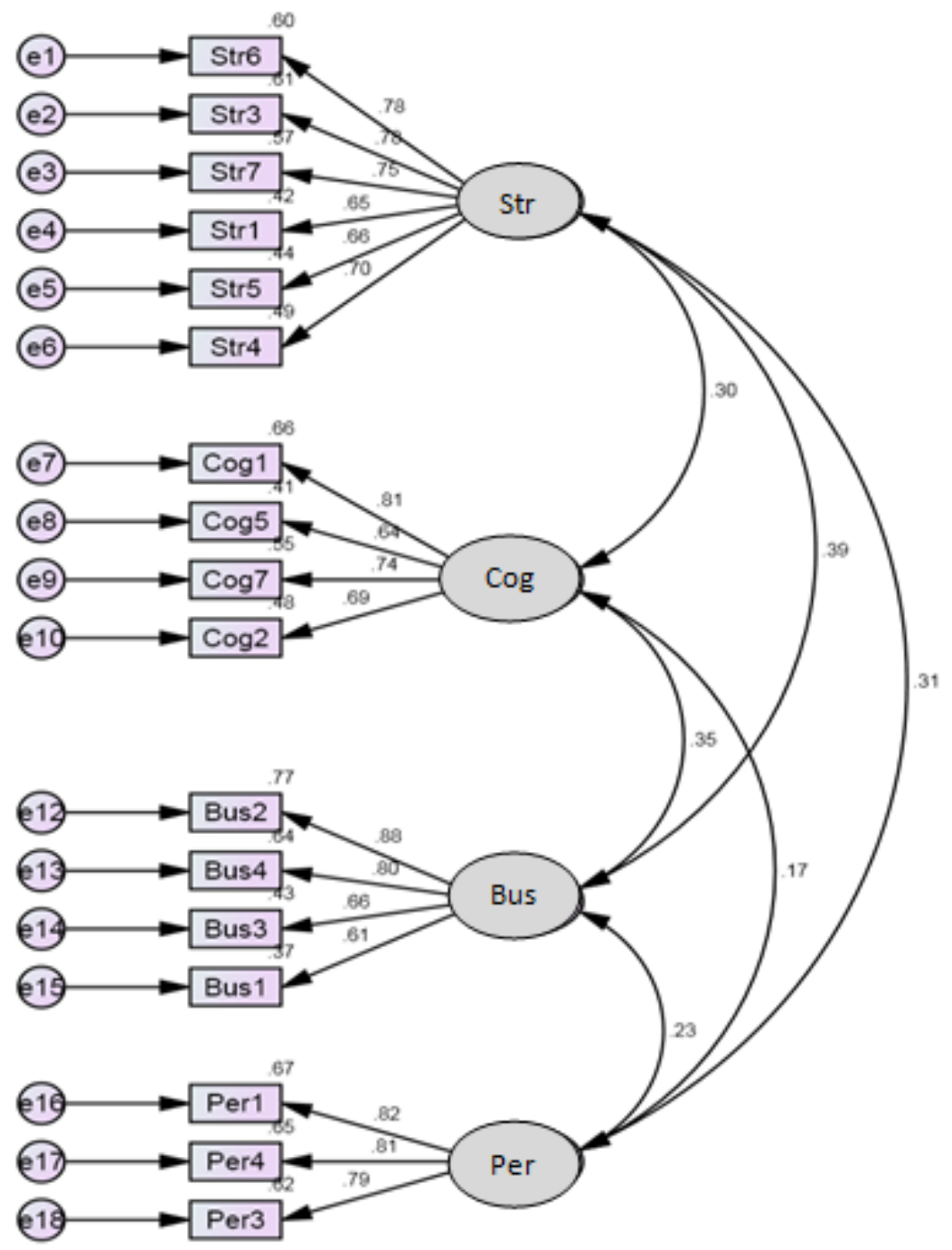

Fig 1: the result of CFA test

The results of the analysis show that the suggested model is appropriate for collected data and can be used to assess leadership skills in Vietnam.

The result of MANCOVA indicated that there were differences in gender (Wilks' Lambda $=.790$, $p$-value $<0.01$ ), in position (Wilks' Lambda $=.429, p$-value $<0.01$ ) and in experience (Wilks' Lambda $=.345, \mathrm{p}-$ value $<0.01)$ according to leadership skills. 


\section{Conclusion and discussion}

Related to the first purpose, the results of this article show that skills of leaders in Vietnam can be assessed cognitive skills, interpersonal skills, business and strategic skills. Cognitive skills are measured speaking, listening, reading comprehension, critical thinking skills. Interpersonal skills are measured social perception, negotiation, persuasion skills. Business skills are measured operations analysis, management of personnel resources, financial resources management, and material resources management skills. Strategic skills are assessed by visioning, system evaluation, identification of downstream consequences, key causes identification, problem identification, and solution appraisal skills.

The average of leaders' these skills self - assessment are not high, 3.6 for cognitive skills, 3.06 for interpersonal skills, 3.36 for business skills, 3.43 for strategic skills. In which, the lowest assessed skills are social perceptiveness skill (3.01), followed by persuasion (3.06), negotiation (3.10), visioning (3.13) and human resource management (3.18) and the best assessed skills are listening (3.76), system evaluation (3.64), operation analysis (3.64), reading comprehension (3.63), and critical thinking (3.54).Detail information is shown in table 5. These results are consistent with previous assessments about leadership skills accomplished by other authors in Vietnam (Do Tien Long 2010; Tran Thi Van Hoa 2012; Le Thi Phuong Thao 2016; Do Anh Duc 2014; Tran Kieu Trang 2012; Ngo Quy Nham 2014).

Related to the second purpose of this paper, there were differences in gender, position and experience years as leader job.

About gender, the results showed that there were a significant difference in gender related to cognitive skills and human skills, and no difference in business skills and strategies skills. In particular, male leaders have higher cognitive skills than female leaders, but women's leaders, on the other hand, outperform male leaders in human skills. Details are shown in Fig 2.

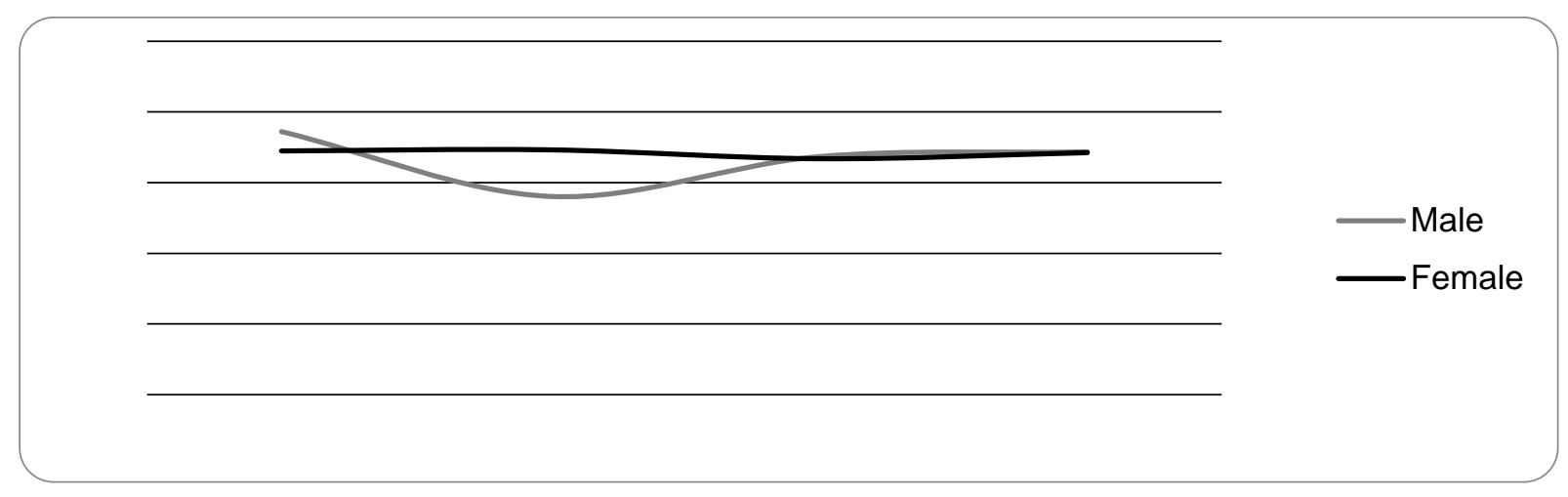

Fig 2: difference in gender about leadership skills

About position, there are usually three levels of leadership, senior leaders, middle and junior leaders in companies. In particular, the higher the leadership levels are, the higher leadership skills are, there is no significant difference in human skills at level. This result is consistent with the results of Mumford, Campion and Morgeson (2007). For senior leaders, cognitive skills and strategic skills are better assessed. At the junior level, strategic skills are somewhat lower than those of higher levels, and lower than cognitive skills, business skills, and human skills. For middle leaders, the leadership skills are the same. This result is accord with the roles and responsibilities of each leader level in the business. Senior leaders often make strategic decisions to maintain and develop the business, middle leaders often coordinate activities, make tactical decisions to achieve goals, and lead. Junior leaders usually make 
operational decisions to urge, instruct, and control employees in their business operations day to day in order to achieve shared goals. Details are indicated in Fig 3.

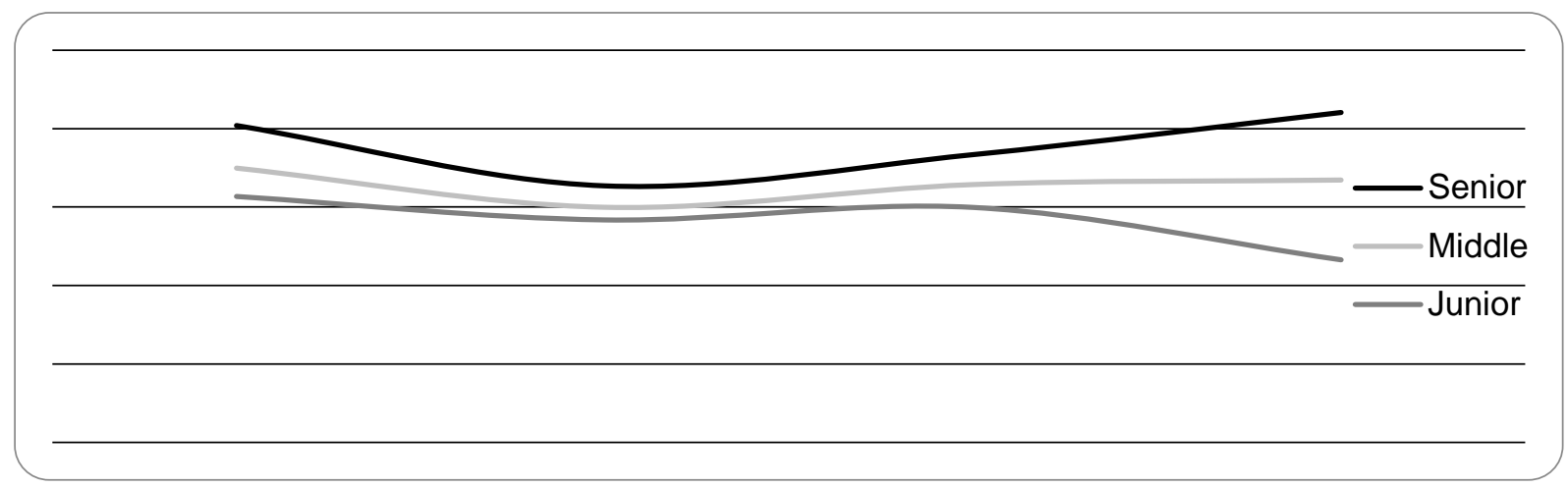

Fig 3: difference in position about leadership skills

About experience, there are differences in leadership skills between leaders who have different experiences years. This result supported for the findings of Mumford et al. (2001), which is that experience influences leadership skills. In particular, the more experience leaders in Vietnam have, the higher leadership skills are. In particular, there are significant differences in strategic skills and business skills. Specifically, strategic skills and business skills of leaders who have 10 years of experience or above are higher than those of leaders who have below 5 experience years. At the same time, cognitive skills and human skills are not significantly different. For leaders who have less than 5 years of experience, strategic skills are weaker than other skills, the cognitive skills, interpersonal and business skills are similar. For leaders who have from five to less than 10 years of experience, four skills are similar. Details are shown in Fig 4.

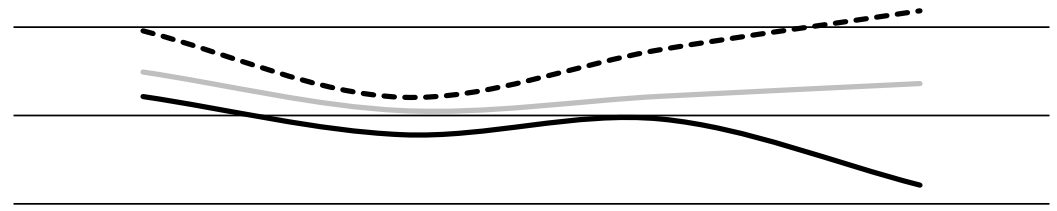

- Under 5 years' experience From 5 to under 10 years' experience -.-.-. From 10 years' experience

Fig 4: difference in experience years about leadership skills

Leadership skills are very important for survival and development of most companies around the world, and it is not easy to fully and accurately assess leadership skills. The results show that leadership skills in Vietnam can be assessed through four main skills: cognitive skills, interpersonal skills, business skills and strategic skills. At the same time, the results show that leadership skills self - assessment at enterprises in HCMC are not high, only over average. In terms of gender, male leaders have higher cognitive skills than female leaders, but in contrast, female leaders are somewhat superior to male leaders in human skills. About position, the higher the leadership levels are, the higher leadership skills 
are, there is no significant difference in human skills at all levels. In experience, leaders have more experience, higher leadership skills, especially strategic skills and business skills. The more experience leaders in Vietnam have, the higher leadership skills are, special in strategic skills and business skills. This study has two major limitations. First, this study concentrates on research in Ho Chi Minh City, one of the economic centers of Vietnam, so the results may be biased when expanding in Vietnam. Second, this paper has not clarified the differences in leadership skills in different sectors. These will be the research directing of author in the future.

\section{References}

[1] Anderson, J. C., \& Gerbing, D. W., 1988. Structural equation modeling in practice: A review and recommended two-step approach. Psychological bulletin, 103(3), 411.

[2] Attewell, P., 1990. What is skill?. Work and occupations, 17(4), pp.422-448.

[3] Bentler, P. M., \& Bonett, D. G., 1980. Significance tests and goodness of fit in the analysis of covariance structures. Psychological bulletin, 88(3), 588.

[4] Campbell, J.P., 1977. The cutting edge of leadership: An overview. Leadership: The cutting edge, pp.221-234.

[5] Cheng, H. C., 2011. Leadership skills and beauty (Doctoral dissertation, Purdue University).

[6] Connelly, M. S., Gilbert, J. A., Zaccaro, S. J., Threlfall, K. V., Marks, M. A., \& Mumford, M. D., 2000. Exploring the relationship of leadership skills and knowledge to leader performance. The Leadership Quarterly, 11(1), 65-86.

[7] Da'as, R. A., 2017. School principals' leadership skills: measurement equivalence across cultures. Compare: A Journal of Comparative and International Education, 47(2), 207-222.

[8] Eagly, A.H., Karau, S.J. and Makhijani, M.G., 1995. Gender and the effectiveness of leaders: A metaanalysis. Psychological bulletin, 117(1), p.125.

[9] Haq, S., 2011. Ethics and leadership skills in the public service. Procedia-Social and Behavioral Sciences, 15, 2792-2796.

[10] House, R.J. and Mansor, N., 1999. Cultural Influences on Leadeership and Organizations: Project Globe (Vol. 1). Advances in Global Leadership.

[11] Hung, N.M., Tesaputa, K. and Sri-ampai, A., Leadership skills of the department heads at a regional university in Vietnam.

[12] Katz, R. L., 1955. Skills of an effective administrator. Harvard business review, 33(1), 33-42.

[13] Kalargyrou, V., Pescosolido, A. T., \& Kalargiros, E. A., 2012. Leadership skills in management education. Academy of Educational Leadership Journal, 16(4), 39.

[14] Karmel, B., 1978. Leadership: A challenge to traditional research methods and assumptions. Academy of Management Review, 3(3), pp.475-482.

[15] Kehinde, J. S., Jegede, C. A., \& Akinlabi, H. B., 2012. Impact of leadership skill and strategies on banking sector performance: A survey of selected consolidated banks in Nigeria. The Business \& Management Review, 3(1), 313.

[16] Likert, R., 1932. A technique for the measurement of attitudes. Archives of psychology.

[17] Lord, R.G., De Vader, C.L. and Alliger, G.M., 1986. A meta-analysis of the relation between personality traits and leadership perceptions: An application of validity generalization procedures. Journal of applied psychology, 71(3), p.402.

[18] Mclver, J., \& Carmines, E. G., 1981. Unidimensional scaling(Vol. 24). Sage.

[19] Moore, L. L., \& Rudd, R. D., 2004. Leadership skills and competencies for extension directors and administrators. Journal of Agricultural Education, 45(3), 22-33. 
[20] Mumford, M. D., Zaccaro, S. J., Harding, F.D., Jacobs, T., \& Fleishman, E. A., 2000. Leadership skills for a changing world: Solving complex problems. The Leadership Quarterly, 11(1), 11-35

[21] Mumford, T. V., Campion, M. A., \& Morgeson, F. P., 2007. The leadership skills strataplex: Leadership skill requirements across organizational levels. The Leadership Quarterly, 18(2), 154166

[22] Nunnally, J. C., \& Bernstein, I. H., 1994. Psychological theory. New York, NY: MacGraw-Hill.

[23] Trang, Nguyen Thi Thu, 2016, Developing leadership skills at non-state enterprises in Vietnam, PhD thesis, Foreign Trade University.

[24] Robbins, C. J., Bradley, E. H., Spicer, M., \& Mecklenburg, G. A., 2001. Developing leadership in healthcare administration: A competency assessment tool/Practitioner application. Journal of Healthcare Management, 46(3), 188

[25] Rost, J.C., 1993. Leadership for the twenty-first century. Greenwood Publishing Group.

[26] Steiger, J. H., 1990. Structural model evaluation and modification: An interval estimation approach. Multivariate behavioral research, 25(2), 173-180.

[27] Stogdill, R.M., 1974. Handbook of leadership: A survey of theory and research. New York, NY, US: Free Press.

[28] Yukl, G. A., 2013. Leadership in organizations. Pearson (Eight Edition)

[29] Zaccaro, S. J., Mumford, M. D., Connelly, M. S., Marks, M. A., \& Gilbert, J. A., 2000. Assessment of leader problem-solving capabilities. The Leadership Quarterly, 11(1), 37-64.

[30] Zilz, D. A., Woodward, B. W., Thielke, T. S., Shane, R. R., \& Scott, B., 2004. Leadership skills for a high-performance. Am J Health-Syst Pharm, 61, 2562-74.

[31] Nguyen Thi Thu Trang;, 2016. Direct research on leadership skills includes PhD thesis on leadership development in non-state enterprises of Vietnam. 


\section{Annexes}

Table 1: Pattern Matrix of EFA test

\begin{tabular}{|c|c|c|c|c|}
\hline \multicolumn{5}{|c|}{ Pattern Matrixa } \\
\hline & \multicolumn{4}{|c|}{ Factor } \\
\hline & 1 & 2 & 3 & 4 \\
\hline Str6 & 0.804 & & & \\
\hline Str3 & 0.792 & & & \\
\hline Str7 & 0.767 & & & \\
\hline Str1 & 0.659 & & & \\
\hline Str5 & 0.653 & & & \\
\hline Str4 & 0.622 & & & \\
\hline $\operatorname{Cog} 1$ & & 0.771 & & \\
\hline $\operatorname{Cog} 5$ & & 0.723 & & \\
\hline $\operatorname{Cog} 7$ & & 0.705 & & \\
\hline $\operatorname{Cog} 2$ & & 0.647 & & \\
\hline $\operatorname{Cog} 3$ & & 0.522 & & \\
\hline Bus2 & & & 0.875 & \\
\hline Bus4 & & & 0.812 & \\
\hline Bus3 & & & 0.665 & \\
\hline Bus1 & & & 0.569 & \\
\hline Per1 & & & & 0.833 \\
\hline Per4 & & & & 0.829 \\
\hline Per3 & & & & 0.769 \\
\hline \multicolumn{5}{|c|}{ Extraction Method: Principal Axis Factoring. } \\
\hline
\end{tabular}


Table 2: Convergent Validity of CFA Test

\begin{tabular}{|c|c|c|c|c|c|c|c|}
\hline & & & Estimate & S.E. & C.R. & $P$ & Label \\
\hline Str6 & $<---$ & Str & 1.000 & & & & \\
\hline Str3 & $<---$ & Str & 1.011 & .073 & 13.929 & $* * *$ & \\
\hline Str7 & $<---$ & Str & 1.005 & .075 & 13.359 & $* * *$ & \\
\hline Str1 & $<---$ & Str & .950 & .083 & 11.384 & $* * *$ & \\
\hline Str5 & $<--$ & Str & .892 & .077 & 11.581 & $* * *$ & \\
\hline Str4 & $<--$ & Str & .820 & .067 & 12.256 & $* * *$ & \\
\hline Cog1 & $<--$ & Cog & 1.000 & & & & \\
\hline Cog5 & $<---$ & Cog & .735 & .068 & 10.730 & $* * *$ & \\
\hline Cog7 & $<---$ & Cog & .925 & .076 & 12.241 & $* * *$ & \\
\hline Cog2 & $<---$ & Cog & .824 & .072 & 11.515 & $* * *$ & \\
\hline Bus2 & $<---$ & Bus & 1.000 & & & & \\
\hline Bus4 & $<---$ & Bus & .937 & .063 & 14.935 & $* * *$ & \\
\hline Bus3 & $<--$ & Bus & .734 & .061 & 12.030 & $* * *$ & \\
\hline Bus1 & $<--$ & Bus & .752 & .068 & 11.068 & $* * *$ & \\
\hline Per1 & $<--$ & Per & 1.000 & & & & \\
\hline Per4 & $<---$ & Per & 1.106 & .079 & 14.080 & $* * *$ & \\
\hline Per3 & $<--$ & Per & 1.085 & .078 & 13.885 & $* * *$ & \\
\hline
\end{tabular}

Table 3: Discriminant Validity of CFA test

\begin{tabular}{|l|c|c|c|c|c|}
\hline & Estimate & S.E. & C.R. & P & Label \\
\hline Str<-->Cog & 0.236 & 0.056 & 4.207 & $* * *$ & \\
\hline Str<-->Bus & 0.247 & 0.045 & 5.476 & $* * *$ & \\
\hline Str<-->Per & 0.169 & 0.039 & 4.359 & $* * *$ & \\
\hline Cog<-->Bus & 0.219 & 0.045 & 4.840 & $* * *$ & \\
\hline Cog<-->Per & 0.095 & 0.038 & 2.481 & 0.013 & \\
\hline Bus<-->Per & 0.101 & 0.030 & 3.356 & $* * *$ & \\
\hline
\end{tabular}

Table 4: Composite reliability and average variance extracted of CFA test

\begin{tabular}{|c|c|c|c|}
\hline Variables & Items & $\begin{array}{c}\text { Composite } \\
\text { reliability }\end{array}$ & $\begin{array}{c}\text { average variance } \\
\text { extracted }\end{array}$ \\
\hline Cog & Cog1, Cog2, Cog5, Cog7 & 0.814 & 0.524 \\
\hline Per & Per1, Per3, Per4 & 0.848 & 0.651 \\
\hline Bus & Bus1, Bus2, Bus3, Bus4 & 0.829 & 0.552 \\
\hline Str & Str1, Str3, Str4, Str5, Str6, Str7 & 0.867 & 0.522 \\
\hline
\end{tabular}

